
motifs (RECK); matrix metalloproteinase (MMP)

\title{
STAT3 upregulates miR-92a to inhibit RECK expression and to promote invasiveness of lung cancer cells
}

H-Y Lin ${ }^{1,3}, \mathrm{C}-\mathrm{H}$ Chiang $^{1,3}$ and W-C Hung ${ }^{\star, 2}$

${ }^{1}$ Institute of Biomedical Sciences, National Sun Yat-Sen University, Kaohsiung 804, Taiwan and ${ }^{2}$ National Institute of Cancer Research, National Health Research Institutes, No. 367, Shengli Road, Tainan 704, Taiwan

Background: Signal transducer and activator of transcription 3 (STAT3) activation is frequently found in human lung cancer and is associated with increased metastasis and reduced survival. How STAT3 enhances invasiveness is unclear.

Methods: The expression of microRNAs and target genes was measured by real-time RT-PCR. Protein level was studied by western blotting. Luciferase reporter assay was used to confirm the direct targeting of microRNAs. Gelatin zymography was used to study matrix metalloproteinase (MMP) activity. Transwell assay was used to investigate cell migration and invasion.

Results: Enforced expression of STAT3 decreases the endogenous MMP inhibitor RECK protein but not mRNA level in H460 cells. Conversely, STAT3 inhibitor S3I-201 increases RECK protein in STAT3-activating H1299 cells. We demonstrate that STAT3 upregulates miR-92a to repress RECK via post-transcriptional inhibition. The RECK $3^{\prime}$-untranslated region (3'UTR) reporter activity assay suggests that RECK is a direct repression target of miR-92a. Delivery of pre-miR-92a reduces RECK protein level whereas transfection of anti-miR-92a restores STAT3-induced downregulation of RECK. Anti-miR-92a attenuates MMP activity, migration and invasion of $\mathrm{H} 1299$ cells and STAT3-overexpressing H460 cells, suggesting miR-92a is critical for STAT3-induced invasiveness.

Conclusion: The STAT3-induced miR-92a promotes cancer invasion by suppressing RECK and targeting of the STAT3/miR-92a axis may be helpful for cancer treatment.

In lung cancer, signal transducer and activator of transcription 3 (STAT3) activation is important for tumour development and promotion (Song et al, 2003; Yeh et al, 2006). The STAT3 is a cytoplasmic transcription factor that can be phosphorylated and activated by growth factors and cytokines. Active STAT3 proteins form homodimer or heterodimer with other transcription factors and translocate into the nucleus, where they bind to specific promoters to induce the expression of target genes like cyclin D1 and Bcl-xl (Bowman et al, 2000; Buettner et al, 2002; Leslie et al, 2006). Activation of STAT3 is frequently found in human lung cancer and is associated with increased metastasis and reduced survival (Haura et al, 2005; Cortas et al, 2007). Recent studies demonstrate that STAT3 stimulates the transcription of matrix metalloproteinase-2 (MMP-2) in melanoma cells to enhance tumour invasion and brain metastasis (Xie et al, 2004). In bladder cancer cells, STAT3 is involved in the induction of MMP-1 by epidermal growth factor (Itoh et al, 2006). Constitutively activated STAT3 also increases MMP-9 activity to enhance the transformation of human mammary epithelial cells (Dechow et al, 2004). These results collectively suggest that upregulation of the activity of MMPs is critical for STAT3-induced invasion and metastasis. However, it should be noted that in vivo MMP activity is controlled by the balance between MMPs and their inhibitory proteins including tissue inhibitor of metalloproteinases and Reversioninducing Cysteine-rich protein with Kazal motifs (RECK) (Noda et al, 2003).

\footnotetext{
*Correspondence: Dr W-C Hung; E-mail: hung1228@nhri.org.tw

${ }^{3}$ These authors contributed equally to this work.
} 
The RECK gene was first identified as a tumour metastasis suppressor, which induced morphological reversion in $\mathrm{v}$-Ki-Rastransformed NIH/3T3 cells (Takahashi et al, 1998). Subsequent studies show that RECK is an endogenous MMP inhibitor and participates in embryonic development (Oh et al, 2001; Noda et al, 2003; Meng et al, 2008; Noda et al, 2010). The expression of RECK is found in most normal human tissues and untransformed cells; however, it is undetectable in many cancers (Masui et al, 2003; Takeuchi et al, 2004). In addition, RECK downregulation is strongly associated with poor prognosis and short survival. We have elucidated the molecular mechanisms by which RECK expression is inhibited by different oncogenes including latent membrane protein 1 (LMP-1) of Epstein-Barr virus (Liu et al, 2003), Ras (Chang et al, 2004) and Her-2/Neu (Hsu et al, 2006). Our data indicate that epigenetic regulation via DNA methylation and histone deacetylation is important for the inhibition of RECK gene transcription by these oncogenes (Chang et al, 2004, 2006). However, only $50-60 \%$ of the lung tumour tissues exhibit RECK promoter methylation, suggesting that other inhibitory mechanisms are involved in the downregulation of RECK in lung cancer (Cho et al, 2007).

MicroRNAs (miRNAs) are endogenous 21-24-nucleotide single-stranded noncoding RNAs that can bind to the $3^{\prime}$-untranslated region ( $3^{\prime}$ UTR) of target mRNAs to induce translation repression or mRNA cleavage and to attenuate protein expression (Esquela-Kerscher and Slack, 2006). Recent studies indicate that miRNAs play important roles in either tumour suppression or promotion (Chan et al, 2005; Iorio et al, 2005; $\mathrm{Ma}$ et al, 2007). Interestingly, RECK has been demonstrated to be a repression target of several miRNAs including miR-21, miR-372/373, miR-222, miR-7 and miR-182 (Gabriely et al, 2008; $\mathrm{Hu}$ et al, 2008; Zhang et al, 2008; Loayza-Puch et al, 2010; Hirata et al, 2012; Jung et al, 2012; Li et al, 2012). Because STAT3 can activate the expression of several miRNAs in various cancers like multiple myeloma, colon cancer and head and neck cancer (Loffler et al, 2007; Iliopoulos et al, 2010; Bourguignon et al, 2012), we study whether STAT3 could inhibit RECK via miRNA to enhance invasiveness of lung cancer cells.

\section{MATERIALS AND METHODS}

Cell lines and reagents. The H460, H1299 and H358 human lung cancer cell lines were obtained from the cell bank of National Health Research Institute (Miaoli, Taiwan). Anti-RECK and anti-STAT3 antibodies were purchased from BD Transduction Laboratories (Franklin Lake, NJ, USA). Anti-phospho-STAT3, anti-Cyclin D1 and anti-integrin $\alpha 5$ were purchased from Cell Signaling Technology (Danvers, MA, USA). Anti-actin and antiFLAG were purchased from Sigma-Aldrich (St Louis, MA, USA). MiR-92a precursor (pre-miR-92a), anti-miR-92a and negative control miRNA were obtained from Ambion (Austin, TX, USA). The STAT3 inhibitor S3I-201 was obtained from Merck (Rockland, MA, USA). Effectene transfection reagent was purchased from QIAGEN (Valencia, CA, USA). Constitutively active STAT3 expression vector RcCMV-S3C was kindly provided by Dr HS Liu (National Cheng Kung University, Tainan, Taiwan).

Establishment of STAT3-activating stable cell lines. The H460 cells were transfected with RcCMV-S3C by Effectene transfection reagent for $72 \mathrm{~h}$ and cultured with medium containing G418 $\left(0.5 \mathrm{mg} \mathrm{ml}^{-1}\right)$ for 3 weeks. The stable clone with highest STAT3 activity (indicated by phospho-STAT3 level) generated by G418 selection was used for subsequent experiments.

RT-PCR and real-time RT-PCR. RNA $(1 \mu \mathrm{g})$ isolated from cells was used to synthesise cDNA by using the NCode VILO miRNA cDNA Synthesis Kit (Invitrogen, Carlsbad, CA, USA). The mRNA and miRNA levels were quantified by using iQ SYBR Green Supermix (Bio-Rad, Hercules, CA, USA) system. The primers used are RECK forward 5' ${ }^{\prime}$ TCTGCAGGGGAAGTTGGTTG-3'; RECK reverse 5'-CAGTTACAGGGCAGACCTGT-3'; miR-92a 5'-CACT TGTCCCGGCCTGT- $3^{\prime}$; and miR-21 $5^{\prime}$-CGGTAGCTTATCA GACTGATGTTGA-3'. Small nuclear RNA U6 and glyceraldehyde 3-phosphate dehydrogenase (GAPDH) were used as internal controls for miRNA and mRNA quantification. Total RNA was also subjected to RT-PCR analysis as described previously (Chang et al, 2006).

Western blot analysis. Cells were transfected with the pre-miRNA and anti-miRNA for $72 \mathrm{~h}$. Cellular proteins were harvested and equal amount of proteins was subjected to SDS-PAGE. Proteins were transferred to nitrocellulose membranes and the blots were probed with different primary antibodies and developed by enhanced chemiluminescence reagents as described previously (Hsu et al, 2008).

Luciferase reporter assay. Control reporter and $3^{\prime}$-UTR reporter plasmid of RECK gene was purchased from GeneCopoeia (Rockville, MD, USA). Reporter plasmids were transfected into cells. After $48 \mathrm{~h}$, luciferase activity was determined and normalised to Renilla luciferase activity as previously described (Chang et al, 2006).

In vitro invasion and migration assay. In vitro invasion and migration assays were performed by using transwell units with polycarbonate filters (pore size $8 \mu \mathrm{m}$ ). The filters were coated with Matrigel (Discovery Labware) on the upper side for invasion assay. Cells were transfected with the anti-miR-92a for $48 \mathrm{~h}$. After that, 5000 cells in $100 \mu \mathrm{l}$ of medium were seeded onto upper well and allowed to invade for $24 \mathrm{~h}$. After incubation, cells on the upper part of the membrane were removed with a cotton swab. Invaded cells on the bottom surface of the membrane were fixed in formaldehyde, stained with Giemsa solution and counted under a microscope.

Gelatin zymography. Cells were transfected with the anti-miR92a for $48 \mathrm{~h}$ and incubated with serum-free medium for another $24 \mathrm{~h}$. Conditioned medium was harvested and zymography assay was done as described previously (Liu et al, 2003).

Statistical analysis. Data were analysed using a two-tailed Student's $t$-test. Differences with a $P$-value of $<0.05$ were considered as significant.

\section{RESULTS}

STAT3 activation negatively regulates RECK expression in human lung cancer cell lines. Expression of STAT3 and RECK in different lung cancer cell lines was studied. As shown in Figure 1A, STAT3 was constitutively activated (as indicated by phosphoSTAT3) in H1299 and H358 and the RECK protein level was very low in these two cell lines. Conversely, H460 cells exhibited low STAT3 activity and high level of RECK protein (Figure 1A). The ratio of phospho-STAT3/STAT3 of H460 cells was reduced to 70\% of that of H1299 cells. Our previous results have demonstrated that transcription of RECK gene was downregulated in H358 cells via promoter methylation (Chang et al, 2006; Cho et al, 2007). This conclusion was reconfirmed by the observation that RECK mRNA level was very low in this cell line (Figure 1A). However, RECK mRNA level of H1299 and H460 cells was comparable whereas RECK protein level was very different, suggesting a post-transcriptional control. Treatment of H1299 cells with different doses of S3I-201, a STAT3 inhibitor, suppressed STAT3 activity and induced downregulation of the STAT3 target gene cyclin D1 (Figure 1B). Interestingly, S3I-201 increased RECK protein level dose-dependently whereas no alteration of mRNA 
level was found (Figure 1B). We established a stable clone from H460 cells by expressing the constitutively active STAT3 (STAT3C) gene. As shown in Figure 1C, STAT3C clone exhibited high STAT3 activity, increased cyclin D1 and reduced RECK protein. S3I-201 attenuated phospho-STAT3 and cyclin D1 whereas it restored RECK protein in STAT3C cells. Again, no change of RECK mRNA level was found. These results suggested that STAT3 may control RECK expression via a post-transcriptional mechanism.

STAT3 transcriptionally upregulates miR-92a in lung cancer cells. The RECK gene has been identified to be a direct target of miR-21 (Gabriely et al, 2008; Hu et al, 2008; Zhang et al, 2008), and miR-21 has been shown to be regulated by STAT3 in several cancer types (Loffler et al, 2007; Iliopoulos et al, 2010; Bourguignon et al, 2012). Therefore, it is reasonable to speculate that STAT3 may increase miR-21 to inhibit RECK in lung cancer. However, our results did not support this hypothesis. First, miR-21 level was similar in H1299 and H460 cells that exhibited very different STAT3 activity (Figure 2A). Second, STAT3C expression did not significantly upregulate miR-21 level in $\mathrm{H} 460$ cells
(Figure 2B). Third, S3I-201 at 50 or $100 \mu \mathrm{m}$ almost completely inhibited phospho-STAT3 in H1299 cells, whereas it only reduced miR-21 level by $20 \%$ and $35 \%$, respectively. We also checked the effect of S3I-201 on the expression of several miRNAs including miR-7, miR-182, miR-222, miR-372 and miR-373 that are known to target RECK mRNA. However, the expression of these miRNAs was not significantly affected by S3I-201 (Supplementary Figure 1). Hence, we searched for other potential miRNAs by bioinformatics analysis using TargetScan and miRanda databases. We found that four potential miR-92a-targeting sites were predicted at the $3^{\prime} \mathrm{UTR}$ of human RECK mRNA (Supplementary Figure 2). One of these sites is highly conserved in different species (Figure 3A). MiR-92a is a member of the miR-17-92 cluster that is located in the third intron of a primary transcript named C13orf25 (Ota et al, 2004). Expression of this cluster has recently been reported to be controlled by STAT3 in HEK293 cell and endothelial cells (Brock et al, 2009). We screened miR-92a expression in H1299, $\mathrm{H} 460$ and H358 cells and found an inverse correlation between miR-92a and STAT3 (Figure 3B). The STAT3 inhibitor S3I-201 suppressed miR-92a expression dose-dependently in H1299 cells (Figure 3C). Enforced expression of Stat3C increased miR-92a
A

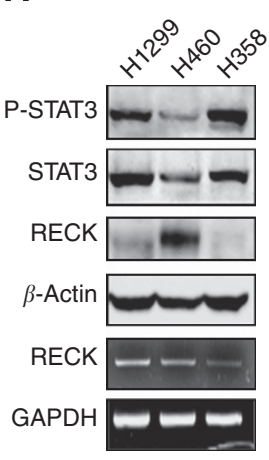

B



C

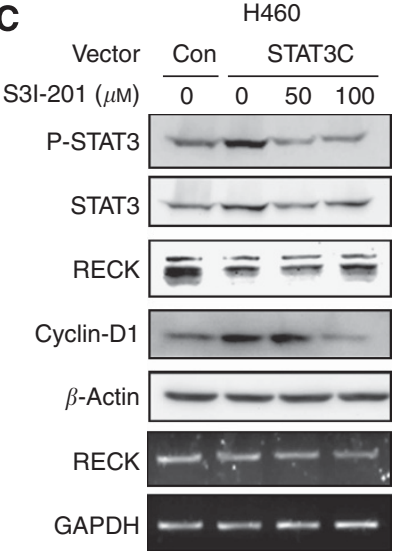

Figure 1. Signal transducer and activator of transcription 3 (STAT3) negatively regulates RECK in lung cancer cells. (A) The levels of RECK, STAT3 and phosphor-STAT3 were detected by western blotting in three human lung cancer cell lines. To investigate RECK mRNA expression, RT-PCR was carried out. (B) The STAT3-activating H1299 cells were treated with different doses of the STAT3 inhibitor S3I-201 for 48 h. Protein and mRNA levels were analysed by western blotting and RT-PCR. Cyclin D1, a transcriptional target of STAT3, was included as a positive control to verify STAT3 activation. (C) The H460 cells were transfected with constitutively active STAT3 expression vector to establish the stable cell line Stat3C. The Stat3C cell line was treated with different doses of S3I-201 for $48 \mathrm{~h}$ and protein and mRNA levels of various genes were analysed by western blotting and RT-PCR.

A

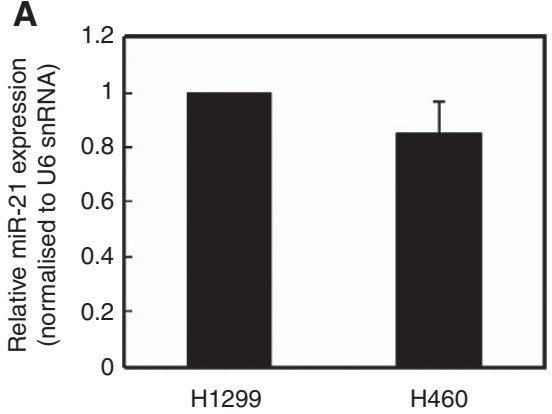

B

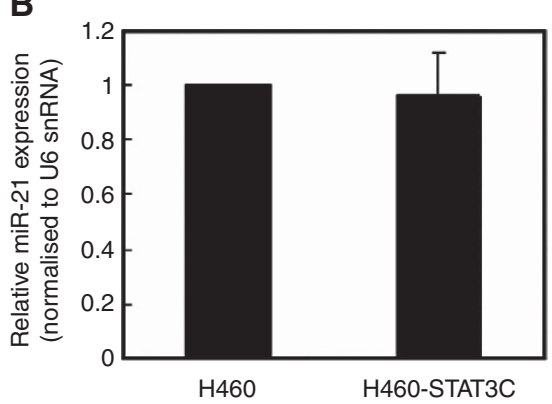

C

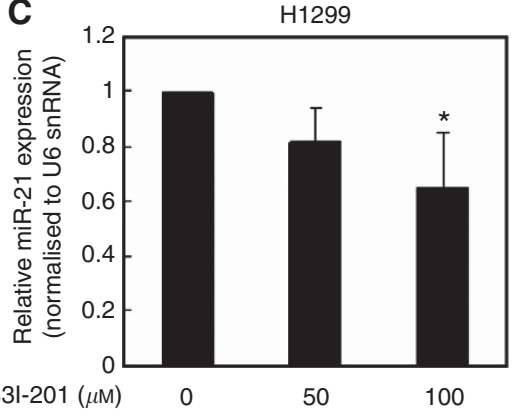

Figure 2. Signal transducer and activator of transcription 3 (STAT3) is not a key regulator of miR-21 in lung cancer cell lines. (A) The expression of miR-21 was detected by real-time RT-PCR and no significant difference was found in H1299 and H460 cell lines. (B) The level of miR-21 of H460 lung cancer cells transfected with control or constitutively active STAT3C vector was compared by real-time RT-PCR analysis. In H460 cells, STAT3C did not significantly upregulate miR-21 level. (C) The STAT3-activiting H1299 cells were treated with different concentrations of S3I-201 for $24 \mathrm{~h}$. The expression of miR-21 was studied and the results of three independent assays were expressed as mean \pm s.e. ${ }^{\star} P<0.05$ when compared with the control group. 
expression in $\mathrm{H} 460$ cells that could be inhibited by S3I-201 (Figure 3D). An increase of microRNAs may result from enhanced transcription or altered biogenesis. Because the mature form of miR-92a was derived from C13orf25 (Figure 4A), we investigated the expression of the transcript. The C13orf25 level of H1299 cells was 1.5-fold higher than that of H460 cells (Figure 4B). S3I-201 suppressed the expression of C13orf25 in H1299 cells in a dose-dependent manner (Figure 4C). Enforced expression of STAT3C upregulated C13orf25 by 1.8 -fold and S3I-201 at the concentration of $100 \mu \mathrm{M}$ completely inhibited this upregulation (Figure 4D). Because the magnitude of change of C13orf25 level was similar to that of miR-92a, we concluded that STAT3 upregulates miR-92a mainly via increase of transcription of its host gene C13orf 25 .
A

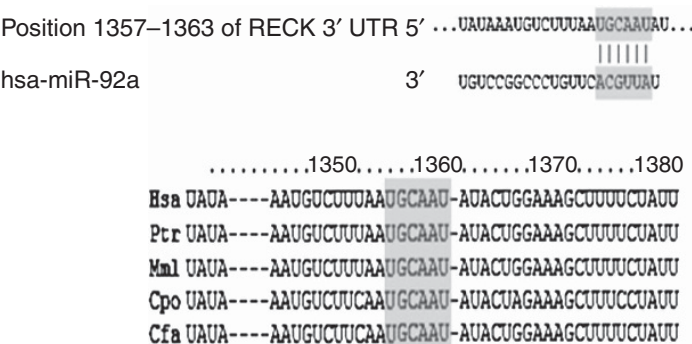

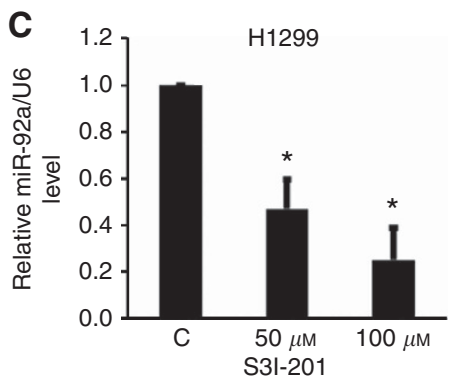

B
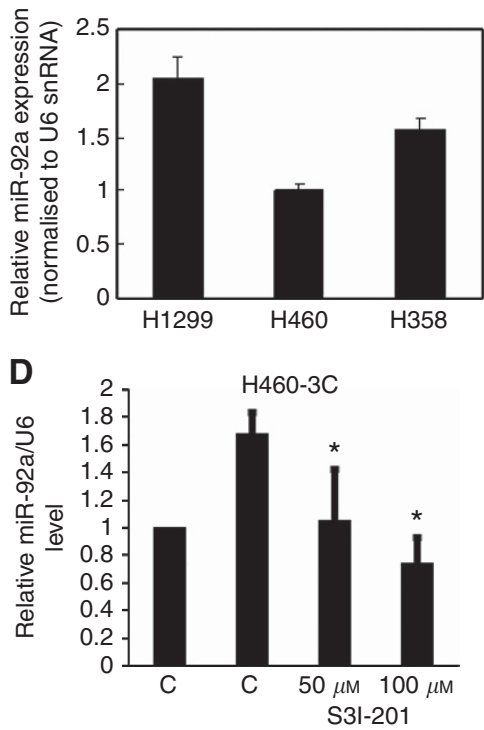

Figure 3. Signal transducer and activator of transcription 3 (STAT3) upregulates miR-92a in lung cancer cells. (A) Bioinformatics analysis identified four miR-92a binding sites in the 3'UTR of RECK mRNA and one of these sites located at 1357-1363 region is highly conserved in different species. (B) The expression of miR-92a was detected by real-time PCR in H1299, H460 and H358 cells. (C) The H1299 cells were treated with different doses of S3I-201 for $48 \mathrm{~h}$ and miR-92a level was analysed by real-time PCR. ${ }^{\star} P<0.05$ when compared with the control group. (D) MiR-92a expression in H460 and H460-STAT3C cells treated with or without S3I-201 was determined by real-time PCR. ${ }^{\star} P<0.05$ when compared with the H460-STAT3C cells treated with vehicle (0.1\% DMSO).

A



C

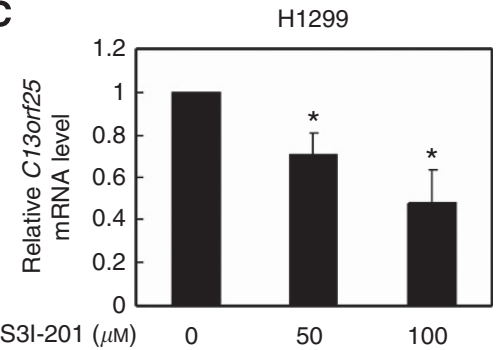

D
B
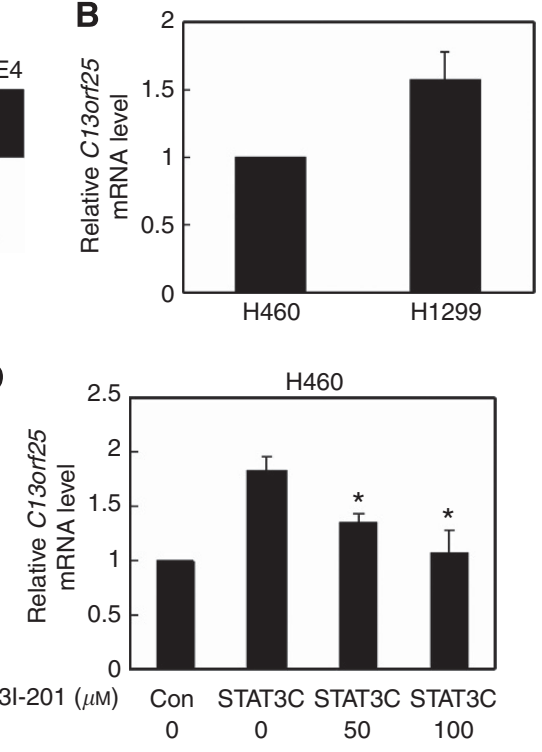

Figure 4. Signal transducer and activator of transcription 3 (STAT3) upregulates miR-92a via increase of transcription of its host gene C13orf25. (A) Diagram showed the structure of C13orf25 gene and the STAT3-binding site in its promoter. MiR-17-92 cluster is located in intron 3. (B) The expression of C13orf25 of $\mathrm{H} 1299$ and $\mathrm{H} 460$ cells was detected by real-time RT-PCR. (C) The H1299 cells were treated with different doses of S3I-201 for $48 \mathrm{~h}$ and $\mathrm{C} 13$ orf25 level was analysed by real-time PCR. ${ }^{\star} P<0.05$ when compared with the control group. (D) Expression of C13orf25 in H460 and H460-STAT3C cells treated with or without S3I-201 was determined by real-time PCR. ${ }^{\star} P<0.05$ when compared with the H460-STAT3C cells treated with vehicle (0.1\% DMSO). 


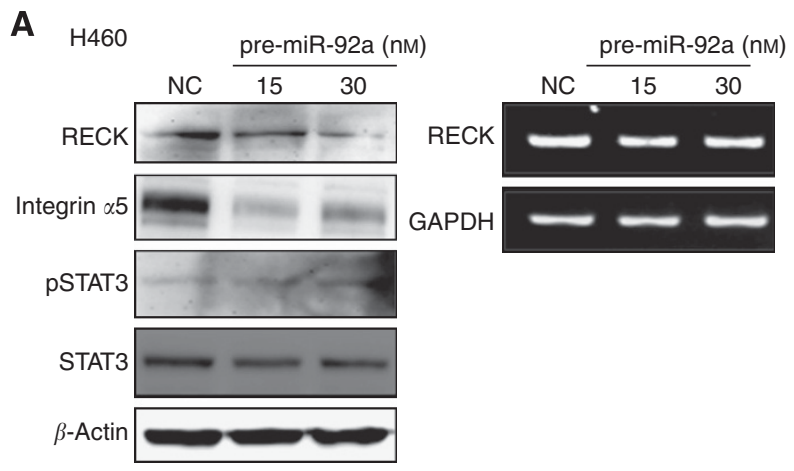

B
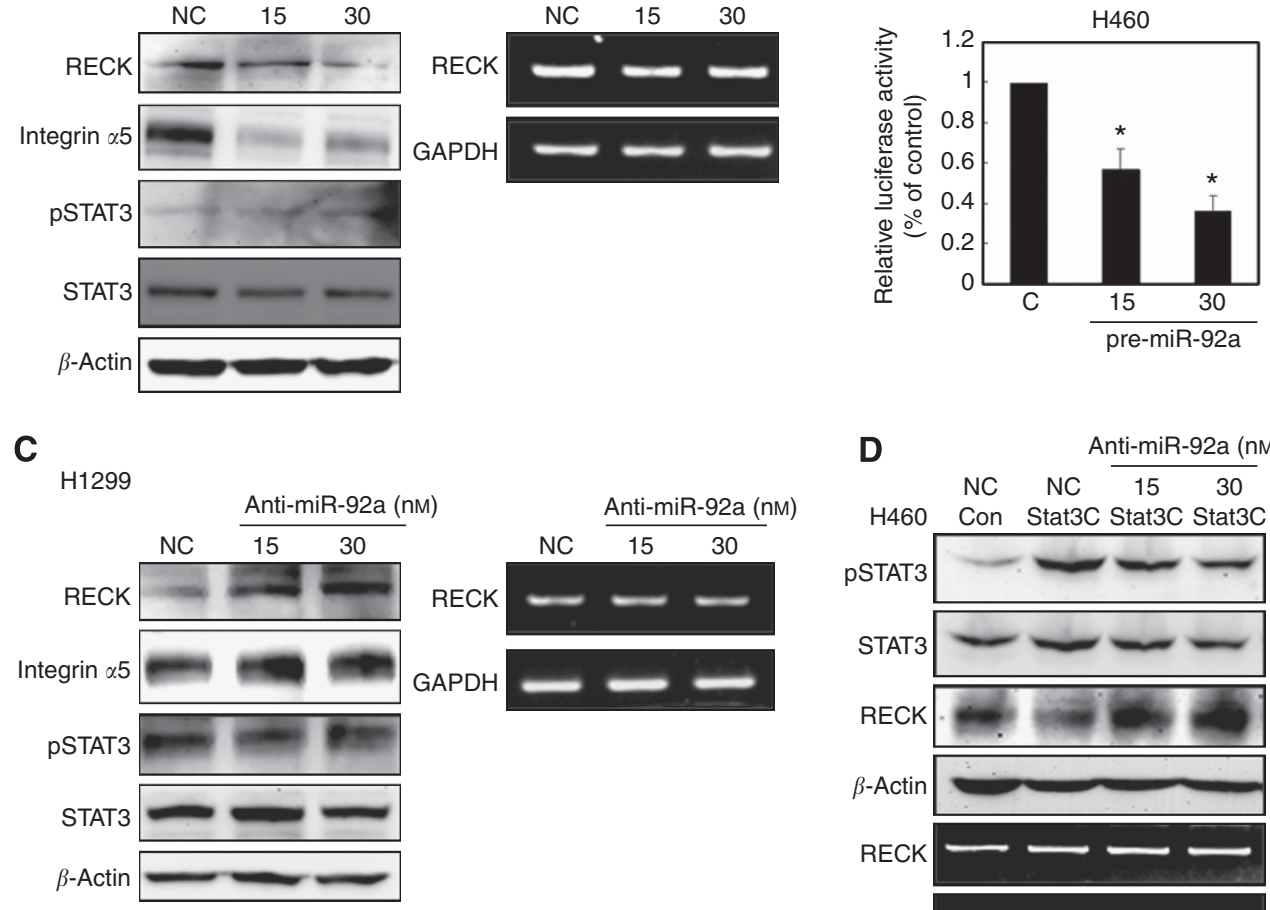

D

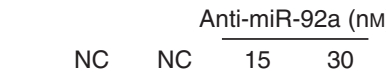

$\mathrm{H} 460$ Con Stat3C Stat3C Stat3C

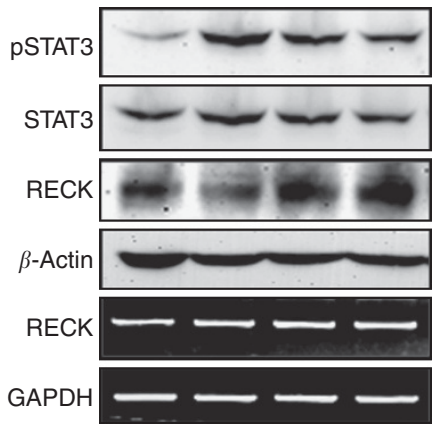

Figure 5. RECK is a direct target of miR-92a. (A) The H460 cells were transfected with pre-miR-92a for $72 \mathrm{~h}$ and the expression of RECK, integrin $\alpha 5$, STAT3 and phospho-STAT3 was analysed by western blotting and RT-PCR. Integrin $\alpha 5$ is a verified target of miR-92a and was included as a positive control. (B) H460 cells were co-transfected with RECK 3'UTR reporter vector and control miRNA (C, $30 \mathrm{~nm}$ ) or pre-miR-92a (15 or $30 \mathrm{~nm}$ ) for $24 \mathrm{~h}$. Luciferase activity was determined and normalised to Renilla luciferase activity. Results from three independent assays were collected and the relative luciferase activity of the control group was defined as $1 .{ }^{\star} \mathrm{P}<0.05$ when compared with the control group. (C) The H1299 cells were transfected with anti-miR-92a for $72 \mathrm{~h}$ and the expression of RECK, integrin $\alpha 5$, STAT3 and phospho-STAT3 was analysed by western blotting and RT-PCR. (D) The H460 and H460-STAT3C cells were transfected with control miRNA (NC, $30 \mathrm{~nm}$ ) or anti-miR-92a (15 or $30 \mathrm{~nm}$ ) for $72 \mathrm{~h}$ and the expression of STAT3 and RECK was analysed by western blotting and RT-PCR.

RECK is a direct target for miR-92a. We next addressed whether RECK is an in vivo target of miR92a. Delivery of pre-miR-92a into H460 cells caused a dose-dependent reduction of RECK protein (Figure 5A). No alteration of RECK mRNA was found suggesting that miR-92a inhibits RECK through translational repression. We also studied the protein level of integrin $\alpha 5$, an identified target of miR-92a, to verify the targeting efficacy of miR-92a in transfected cells. Indeed, integrin $\alpha 5$ level was attenuated (Figure 5A). Anti-miR-92a did not affect STAT3 expression or activation, suggesting that STAT3 is an upstream regulator of miR-92a (Figure 5A). When RECK $3^{\prime} \mathrm{UTR}$ reporter vector was co-transfected with pre-miR-92a, reporter activity was inhibited dose-dependently in $\mathrm{H} 460$ cells (Figure 5B). These results suggest that RECK is a direct target of miR-92a. As shown in Figure 5C, anti-miR-92a reversed RECK and integrin $\alpha 5$ protein level in H1299 cells. Ectopic expression of STAT3C induced downregulation of RECK protein in $\mathrm{H} 460$ cells that could be reversed by co-transfection of anti-miR-92a (Figure 5D). Collectively, we conclude that STAT3 activation suppresses RECK expression by upregulating miR-92a.

MiR-92a is critical for STAT3-induced MMP activity, migration and invasion. Different functional assays were used to clarify the importance of miR-92 in the enhancement of invasiveness by STAT3. Delivery of anti-miR-92a decreased MMP-2 and MMP-9 activity as assessed by gelatin zymography in H1299 cells (Figure 6A). In accordance with the downregulation of MMP activity, cell migration and invasion were also reduced dose-dependently. Anti-miR-92a at $30 \mathrm{~nm}$ inhibited the number of migrated and invade cells by $\sim 55 \%$ and $42 \%$, respectively (Figure 6B). The H460 cells exhibited very low MMP-2 and MMP-9 activity (Figure 6C). Enforced expression of Stat3C in these cells dramatically increased MMP activity that was accompanied with enhanced migration and invasion (Figure 6D). All these increases were inhibited by anti-miR-92a. These results suggested that miR-92a is a critical mediator for STAT3 to promote MMP activity, invasion and migration.

\section{DISCUSSION}

The first important finding of our study is that we identify STAT3 as a key regulator that activates miR-17-92 expression in human lung cancer cells. The miR-17-92 cluster is a polycistronic miRNA gene located on the chromosome 13q31-q32 (Ota et al, 2004). This cluster encodes six miRNAs (miR-17, miR-18a, miR-19a, miR-20a, miR-19b-1 and miR-92a) that gathered within 800 base pair region in the intron 3 of the host gene known as C13orf25 (Ota et al, 2004). Mice deficient for miR-17-92 die shortly after birth with abnormalities including lung hypoplasia, ventricular septal defect and increased B-cell apoptosis (Ventura et al, 2008). These data suggest the physiological importance of miR-17-92 cluster in development. Interestingly, miR-17-92 also participates in carcinogenesis. Hayashita et al (2005) demonstrate that miR-17-92 is markedly overexpressed in human lung cancer tissues and cell lines. Antisense inhibition of two cluster members miR-17 and 
A H1299

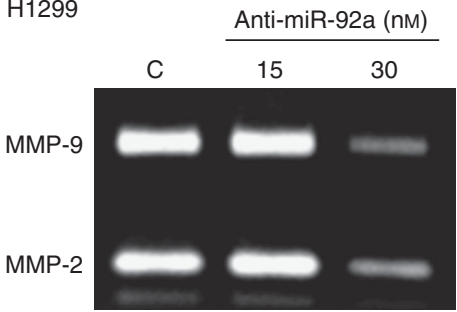

B


C $\mathrm{H} 460$

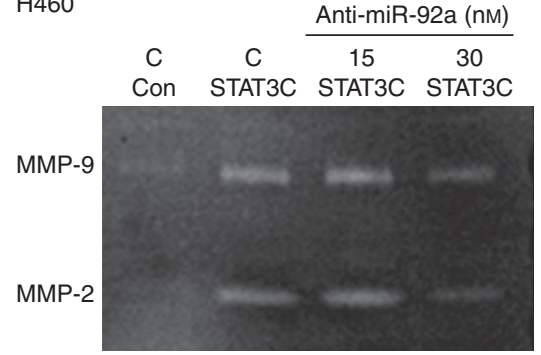

D $\mathrm{H} 460$


Figure 6. MiR-92a is critical for STAT3-induced MMP activity, migration and invasion in lung cancer cells. The H1299 cells were transfected with control miRNA (C, $30 \mathrm{~nm}$ ) or anti-miR-92a (15 or $30 \mathrm{~nm}$ ) for $72 \mathrm{~h}$. The conditioned medium was harvested and subjected to zymography assay (A). The cells were harvested simultaneously for invasion and migration assay (B). ${ }^{*} P<0.05$ when compared with the control group. (C) The H460 or H460-STAT3C cells were transfected with control miRNA (C, $30 \mathrm{~nm}$ ) or anti-miR-92a (15 or $30 \mathrm{~nm}$ ) for $72 \mathrm{~h}$ and the conditioned medium was harvested and subjected to zymography assay. The cell was also harvested for invasion and migration assay (D). *P<0.05 when compared with the H460-STAT3C cells transfected with control miRNA.

miR-20 leads to increased apoptosis in lung cancer cells, suggesting that this cluster functions as a critical regulator in the proliferation or survival of lung cancer cells (Matsubara et al, 2007). Consistent with this hypothesis, forced expression of miR-17-92 under the control of surfactant protein C (a lung-specific gene) promoter causes hyperproliferation and blocks differentiation of the lung epithelium in vivo ( $\mathrm{Lu}$ et al, 2007). However, the molecular mechanisms underlying miR-17-92 overexpression in lung cancer are still unclear. Amplification of the chromosome 13q31-32 region only occurs in a minor portion of lung cancer (Hayashita et al, 2005). c-Myc has been shown to activate miR-17-92 cluster in B-cell lymphoma (He et al, 2005a,b). However, upregulation of c-Myc is detected in $<20 \%$ of lung tumours (Wu et al, 1998). The E2F transcription factors have also been demonstrated to activate miR-17-92 expression (Sylvestre et al, 2007; Woods et al, 2007). Interestingly, miR-17 and miR-20 inhibit E2F via a feedback loop. Whether this feedback loop plays any role in lung cancer is unclear. We demonstrate that STAT3 upregulates transcription of C13orf25 and increases expression of miR-92a in lung cancer cells. Because the magnitude of increase of miR-92a is very similar to that of C13orf25, we conclude that upregulation of miR92a by STAT3 is caused by transcriptional activation of its host gene. In $\sim 40 \%$ of lung tumour tissues, STAT3 is activated (Cortas et al, 2007). Therefore, it may represent a main upstream regulator that induces miR-92a overexpression in lung cancer.

Another important finding is that we identify RECK as an in vivo target of miR-92a. Although the six miRNAs encoded by the miR-17-92 cluster are generally coexpressed with its host gene C13orf25, these miRNAs have been reported to be differentially expressed in different cancers (Venturini et al, 2007; Connolly et al, 2008; Takakura et al, 2008; Mi et al, 2010). In addition, these
miRNAs are divided into four subfamilies based on their seed sequences. MiR-17 and miR-20 have the same seed sequence (AAAGUG from nucleotides 2-7) and are the best-characterised miRNAs in this cluster. These two miRNAs exhibit oncogenic activity by targeting different tumour-suppressor genes including retinoblastoma (RB), p21, Bim and JNK2 to enhance proliferation and survival of cancer cells (Cloonan et al, 2008; Takakura et al, 2008). MiR-18a with a seed sequence of AAGGUG has been shown to regulate angiogenesis by inhibiting two antiangiogenic proteins thromospondin-1 and connective tissue growth factor (Dews et al, 2006). MiR-92a is the last and least described member of the miR-17-92 cluster. Overexpression of this miRNA is found in hepatocellular carcinoma, neuroblastoma and colorectal cancer (Shigoka et al, 2010; Nishida et al, 2012). However, only two target genes of miR-92a have been verified until now because this miRNA exhibits a unique seed sequence that is different from that of other cluster members. The first is Bcl-2-interacting mediator of cell death (BIM) in colorectal cancer (Tsuchida et al, 2011). MiR-92a was transcribed at higher levels than the other five miRNAs of the miR-17-92 cluster in colon adenoma and carcinoma. Delivery of anti-miR-92a induced apoptosis in colon cancer cell lines, suggesting an anti-apoptotic role of this miRNA. The second is DICKKOPF-3 (DKK3) in neuroblastoma (Haug et al, 2011). The DKK3 is a secreted protein with anticancer activity by antagonising the Wnt signaling pathway (Hoang et al, 2004; Lee et al, 2009). In neuroblastoma cell lines, N-MYC activation upregulated miR-92a expression and reduced DKK3 protein level. Investigation of neuroblastoma tissues revealed an inverse association between DKK3 mRNA and miR-92a. However, no functional assays were done to elucidate the role of DKK3 in neuroblastoma cells. In this study, we provide the first evidence that RECK is an in vivo target 
of miR-92a. Among the miR-17-92 members, only miR-92a was predicted to target the $3^{\prime}$ UTR of RECK mRNA. Our cell-based assay confirms the importance of miR-92a in STAT3-induced downregulation of RECK. In STAT3-activated lung cancer cells, anti-miR-92a significantly reduced migration and invasion without affecting cell viability. Therefore, the oncogenic activity of miR-92a is cell type and context dependent.

The control of invasion of lung cancer cells by the STAT3/ miR-92a axis provides new strategies for treatment. Development of STAT3 inhibitors or decoys is a hot area in drug development. Several STAT3 inhibitors are in early-phase clinical trials (Debnath et al, 2012). For example, Pyrimethamine is tested for the treatment for relapsed chronic lymphocytic leukaemia and small lymphocytic lymphoma (NCT01066663, http://ClinicalTrials.gov). Another compound, OPB-31121, is also undergoing phase I/II trials for the therapy of pancreatic cancer (NCT00529113, http:// ClinicalTrials.gov). It is expected that more STAT3 inhibitors will be developed for cancer treatment. Another potential strategy is siRNA therapy. Targeting of $\beta$-catenin, PLK1, Furin, RRM2, Bcl-2 and VEGF by siRNAs are tested in early-phase clinical trials (Davidson \& McCray, 2011). Whether miR-92a is a rational target for cancer therapy warrants further studies. In conclusion, we demonstrate for the first time that STAT3 activation leads to miR-92a overexpression in lung cancer cells and miR-92a mediates STAT3-induced MMP activity and invasiveness by inhibiting RECK.

\section{ACKNOWLEDGEMENTS}

This study was supported by Grants NSC 96-2628-B-110-001-MY3 and 99-2628-B-400-004-MY3 of National Science Council, Taiwan. This study was also supported by Grants DOH 102-TD-C-111-002 and DOH 102-TD-C-111-004 from Department of Health, Taiwan, Republic of China.

\section{CONFLICT OF INTEREST}

The authors declare no conflict of interest.

\section{REFERENCES}

Bourguignon LY, Earle C, Wong G, Spevak CC, Krueger K (2012) Stem cell marker (Nanog) and Stat-3 signaling promote MicroRNA-21 expression and chemoresistance in hyaluronan/CD44-activated head and neck squamous cell carcinoma cells. Oncogene 31(2): 149-160.

Bowman T, Garcia R, Turkson J, Jove R (2000) STATs in oncogenesis. Oncogene 19(21): 2474-2488.

Brock M, Trenkmann M, Gay RE, Michel BA, Gay S, Fischler M, Ulrich S, Speich R, Huber LC (2009) Interleukin-6 modulates the expression of the bone morphogenic protein receptor type II through a novel STAT3microRNA cluster 17/92 pathway. Circ Res 104(10): 1184-1191.

Buettner R, Mora LB, Jove R (2002) Activated STAT signaling in human tumors provides novel molecular targets for therapeutic intervention. Clin Cancer Res 8(4): 945-954.

Chan JA, Krichevsky AM, Kosik KS (2005) MicroRNA-21 is an antiapoptotic factor in human glioblastoma cells. Cancer Res 65(14): 6029-6033.

Chang HC, Cho CY, Hung WC (2006) Silencing of the metastasis suppressor RECK by RAS oncogene is mediated by DNA methyltransferase 3b-induced promoter methylation. Cancer Res 66(17): 8413-8420.

Chang HC, Liu LT, Hung WC (2004) Involvement of histone deacetylation in ras-induced down-regulation of the metastasis suppressor RECK. Cell Signal 16(6): 675-679.

Cho CY, Wang JH, Chang HC, Chang CK, Hung WC (2007) Epigenetic inactivation of the metastasis suppressor RECK enhances invasion of human colon cancer cells. J Cell Physiol 213(1): 65-69.
Cloonan N, Brown MK, Steptoe AL, Wani S, Chan WL, Forrest AR, Kolle G, Gabrielli B, Grimmond SM (2008) The miR-17-5p microRNA is a key regulator of the G1/S phase cell cycle transition. Genome Biol 9(8): R127.

Connolly E, Melegari M, Landgraf P, Tchaikovskaya T, Tennant BC, Slagle BL, Rogler LE, Zavolan M, Tuschl T, Rogler CE (2008) Elevated expression of the miR-17-92 polycistron and miR-21 in hepadnavirus-associated hepatocellular carcinoma contributes to the malignant phenotype. Am J Pathol 173(3): 856-864.

Cortas T, Eisenberg R, Fu P, Kern J, Patrick L, Dowlati A (2007) Activation state EGFR and STAT-3 as prognostic markers in resected non-small cell lung cancer. Lung Cancer 55(3): 349-355.

Davidson BL, McCray Jr PB (2011) Current prospects for RNA interferencebased therapies. Nat Rev Genet 12(5): 329-340.

Debnath B, Xu S, Neamati N (2012) Small molecule inhibitors of signal transducer and activator of transcription 3 (Stat3) protein. J Med Chem 55(15): 6645-6668.

Dechow TN, Pedranzini L, Leitch A, Leslie K, Gerald WL, Linkov I, Bromberg JF (2004) Requirement of matrix metalloproteinase-9 for the transformation of human mammary epithelial cells by Stat3-C. Proc Natl Acad Sci USA 101(29): 10602-10607.

Dews M, Homayouni A, Yu D, Murphy D, Sevignani C, Wentzel E, Furth EE, Lee WM, Enders GH, Mendell JT, Thomas-Tikhonenko A (2006) Augmentation of tumor angiogenesis by a Myc-activated microRNA cluster. Nat Genet 38(9): 1060-1065.

Esquela-Kerscher A, Slack FJ (2006) Oncomirs-microRNAs with a role in cancer. Nat Rev Cancer 6(4): 259-269.

Gabriely G, Wurdinger T, Kesari S, Esau CC, Burchard J, Linsley PS, Krichevsky AM (2008) MicroRNA 21 promotes glioma invasion by targeting matrix metalloproteinase regulators. Mol Cell Biol 28(17): 5369-5380.

Haug BH, Henriksen JR, Buechner J, Geerts D, Tomte E, Kogner P, Martinsson T, Flaegstad T, Sveinbjornsson B, Einvik C (2011) MYCN-regulated miRNA-92 inhibits secretion of the tumor suppressor DICKKOPF-3 (DKK3) in neuroblastoma. Carcinogenesis 32(7): $1005-1012$.

Haura EB, Zheng Z, Song L, Cantor A, Bepler G (2005) Activated epidermal growth factor receptor-Stat-3 signaling promotes tumor survival in vivo in non-small cell lung cancer. Clin Cancer Res 11(23): 8288-8294.

Hayashita Y, Osada H, Tatematsu Y, Yamada H, Yanagisawa K, Tomida S, Yatabe Y, Kawahara K, Sekido Y, Takahashi T (2005) A polycistronic microRNA cluster, miR-17-92, is overexpressed in human lung cancers and enhances cell proliferation. Cancer Res 65(21): 9628-9632.

He H, Jazdzewski K, Li W, Liyanarachchi S, Nagy R, Volinia S, Calin GA, Liu CG, Franssila K, Suster S, Kloos RT, Croce CM, de la Chapelle A (2005a) The role of microRNA genes in papillary thyroid carcinoma. Proc Natl Acad Sci USA 102(52): 19075-19080.

He L, Thomson JM, Hemann MT, Hernando-Monge E, Mu D, Goodson S, Powers S, Cordon-Cardo C, Lowe SW, Hannon GJ, Hammond SM (2005b) A microRNA polycistron as a potential human oncogene. Nature 435(7043): 828-833.

Hirata H, Ueno K, Shahryari V, Tanaka Y, Tabatabai ZL, Hinoda Y, Dahiya R (2012) Oncogenic miRNA-182-5p targets Smad4 and RECK in human bladder cancer. PLoS One 7(11): e51056.

Hoang BH, Kubo T, Healey JH, Yang R, Nathan SS, Kolb EA, Mazza B, Meyers PA, Gorlick R (2004) Dickkopf 3 inhibits invasion and motility of Saos-2 osteosarcoma cells by modulating the Wnt-beta-catenin pathway. Cancer Res 64(8): 2734-2739.

Hsu MC, Chang HC, Hung WC (2006) HER-2/neu represses the metastasis suppressor RECK via ERK and Sp transcription factors to promote cell invasion. J Biol Chem 281(8): 4718-4725.

Hsu MC, Huang CC, Chang HC, Hu TH, Hung WC (2008) Overexpression of Jab1 in hepatocellular carcinoma and its inhibition by peroxisome proliferator-activated receptor\{gamma\} ligands in vitro and in vivo. Clin Cancer Res 14(13): 4045-4052.

Hu SJ, Ren G, Liu JL, Zhao ZA, Yu YS, Su RW, Ma XH, Ni H, Lei W, Yang ZM (2008) MicroRNA expression and regulation in mouse uterus during embryo implantation. J Biol Chem 283(34): 23473-23484.

Iliopoulos D, Jaeger SA, Hirsch HA, Bulyk ML, Struhl K (2010) STAT3 activation of miR-21 and miR-181b-1 via PTEN and CYLD are part of the epigenetic switch linking inflammation to cancer. Mol Cell 39(4): 493-506.

Iorio MV, Ferracin M, Liu CG, Veronese A, Spizzo R, Sabbioni S, Magri E, Pedriali M, Fabbri M, Campiglio M, Menard S, Palazzo JP, Rosenberg A, Musiani P, Volinia S, Nenci I, Calin GA, Querzoli P, Negrini M, Croce CM 
(2005) MicroRNA gene expression deregulation in human breast cancer. Cancer Res 65(16): 7065-7070.

Itoh M, Murata T, Suzuki T, Shindoh M, Nakajima K, Imai K, Yoshida K (2006) Requirement of STAT3 activation for maximal collagenase-1 (MMP-1) induction by epidermal growth factor and malignant characteristics in T24 bladder cancer cells. Oncogene 25(8): 1195-1204.

Jung HM, Phillips BL, Patel RS, Cohen DM, Jakymiw A, Kong WW, Cheng JQ, Chan EK (2012) Keratinization-associated miR-7 and miR-21 regulate tumor suppressor reversion-inducing cysteine-rich protein with kazal motifs (RECK) in oral cancer. J Biol Chem 287(35): 29261-29272.

Lee W, Swarup S, Chen J, Ishitani T, Verheyen EM (2009) Homeodomaininteracting protein kinases (Hipks) promote $\mathrm{Wnt} / \mathrm{Wg}$ signaling through stabilization of beta-catenin/Arm and stimulation of target gene expression. Development 136(2): 241-251.

Leslie K, Lang C, Devgan G, Azare J, Berishaj M, Gerald W, Kim YB, Paz K, Darnell JE, Albanese C, Sakamaki T, Pestell R, Bromberg J (2006) Cyclin $\mathrm{D} 1$ is transcriptionally regulated by and required for transformation by activated signal transducer and activator of transcription 3. Cancer Res 66(5): 2544-2552.

Li N, Tang B, Zhu ED, Li BS, Zhuang Y, Yu S, Lu DS, Zou QM, Xiao B, Mao XH (2012) Increased miR-222 in H. pylori-associated gastric cancer correlated with tumor progression by promoting cancer cell proliferation and targeting RECK. FEBS Lett 586(6): 722-728.

Liu LT, Peng JP, Chang HC, Hung WC (2003) RECK is a target of Epstein-Barr virus latent membrane protein 1. Oncogene 22(51): 8263-8270.

Loayza-Puch F, Yoshida Y, Matsuzaki T, Takahashi C, Kitayama H, Noda M (2010) Hypoxia and RAS-signaling pathways converge on, and cooperatively downregulate, the RECK tumor-suppressor protein through microRNAs. Oncogene 29(18): 2638-2648.

Loffler D, Brocke-Heidrich K, Pfeifer G, Stocsits C, Hackermuller J, Kretzschmar AK, Burger R, Gramatzki M, Blumert C, Bauer K, Cvijic H, Ullmann AK, Stadler PF, Horn F (2007) Interleukin-6 dependent survival of multiple myeloma cells involves the Stat3-mediated induction of microRNA-21 through a highly conserved enhancer. Blood 110(4): 1330-1333.

Lu Y, Thomson JM, Wong HY, Hammond SM, Hogan BL (2007) Transgenic over-expression of the microRNA miR-17-92 cluster promotes proliferation and inhibits differentiation of lung epithelial progenitor cells. Dev Biol 310(2): 442-453.

Ma L, Teruya-Feldstein J, Weinberg RA (2007) Tumour invasion and metastasis initiated by microRNA-10b in breast cancer. Nature $\mathbf{4 4 9}(7163)$ $682-688$.

Masui T, Doi R, Koshiba T, Fujimoto K, Tsuji S, Nakajima S, Koizumi M, Toyoda E, Tulachan S, Ito D, Kami K, Mori T, Wada M, Noda M, Imamura M (2003) RECK expression in pancreatic cancer: its correlation with lower invasiveness and better prognosis. Clin Cancer Res 9(5): 1779-1784.

Matsubara H, Takeuchi T, Nishikawa E, Yanagisawa K, Hayashita Y, Ebi H, Yamada H, Suzuki M, Nagino M, Nimura Y, Osada H, Takahashi T (2007) Apoptosis induction by antisense oligonucleotides against miR-17-5p and miR-20a in lung cancers overexpressing miR-17-92. Oncogene 26(41): 6099-6105.

Meng N, Li Y, Zhang H, Sun XF (2008) RECK, a novel matrix metalloproteinase regulator. Histol Histopathol 23(8): 1003-1010.

Mi S, Li Z, Chen P, He C, Cao D, Elkahloun A, Lu J, Pelloso LA, Wunderlich M, Huang H, Luo RT, Sun M, He M, Neilly MB, Zeleznik-Le NJ, Thirman MJ, Mulloy JC, Liu PP, Rowley JD, Chen J (2010) Aberrant overexpression and function of the miR-17-92 cluster in MLL-rearranged acute leukemia. Proc Natl Acad Sci USA 107(8): 3710-3715.

Nishida N, Nagahara M, Sato T, Mimori K, Sudo T, Tanaka F, Shibata K, Ishii H, Sugihara K, Doki Y, Mori M (2012) Microarray analysis of colorectal cancer stromal tissue reveals upregulation of two oncogenic miRNA clusters. Clin Cancer Res 18(11): 3054-3070.

Noda M, Oh J, Takahashi R, Kondo S, Kitayama H, Takahashi C (2003) RECK: a novel suppressor of malignancy linking oncogenic signaling to extracellular matrix remodeling. Cancer Metastasis Rev 22(2-3): $167-175$.

Noda M, Takahashi C, Matsuzaki T, Kitayama H (2010) What we learn from transformation suppressor genes: lessons from RECK. Future Oncol 6(7): 1105-1116.
Oh J, Takahashi R, Kondo S, Mizoguchi A, Adachi E, Sasahara RM, Nishimura S, Imamura Y, Kitayama H, Alexander DB, Ide C, Horan TP, Arakawa T, Yoshida H, Nishikawa S, Itoh Y, Seiki M, Itohara S, Takahashi C, Noda M (2001) The membrane-anchored MMP inhibitor RECK is a key regulator of extracellular matrix integrity and angiogenesis. Cell 107(6): 789-800.

Ota A, Tagawa H, Karnan S, Tsuzuki S, Karpas A, Kira S, Yoshida Y, Seto M (2004) Identification and characterization of a novel gene, C13orf25, as a target for 13q31-q32 amplification in malignant lymphoma. Cancer Res 64(9): 3087-3095.

Shigoka M, Tsuchida A, Matsudo T, Nagakawa Y, Saito H, Suzuki Y, Aoki T, Murakami Y, Toyoda H, Kumada T, Bartenschlager R, Kato N, Ikeda M, Takashina T, Tanaka M, Suzuki R, Oikawa K, Takanashi M, Kuroda M (2010) Deregulation of miR-92a expression is implicated in hepatocellular carcinoma development. Pathol Int 60(5): 351-357.

Song L, Turkson J, Karras JG, Jove R, Haura EB (2003) Activation of Stat3 by receptor tyrosine kinases and cytokines regulates survival in human non-small cell carcinoma cells. Oncogene 22(27): 4150-4165.

Sylvestre Y, De Guire V, Querido E, Mukhopadhyay UK, Bourdeau V, Major F, Ferbeyre G, Chartrand P (2007) An E2F/miR-20a autoregulatory feedback loop. J Biol Chem 282(4): 2135-2143.

Takahashi C, Sheng Z, Horan TP, Kitayama H, Maki M, Hitomi K, Kitaura Y, Takai S, Sasahara RM, Horimoto A, Ikawa Y, Ratzkin BJ, Arakawa T, Noda M (1998) Regulation of matrix metalloproteinase-9 and inhibition of tumor invasion by the membrane-anchored glycoprotein RECK. Proc Natl Acad Sci USA 95(22): 13221-13226.

Takakura S, Mitsutake N, Nakashima M, Namba H, Saenko VA, Rogounovitch TI, Nakazawa Y, Hayashi T, Ohtsuru A, Yamashita S (2008) Oncogenic role of miR-17-92 cluster in anaplastic thyroid cancer cells. Cancer Sci 99(6): 1147-1154.

Takeuchi T, Hisanaga M, Nagao M, Ikeda N, Fujii H, Koyama F, Mukogawa T, Matsumoto H, Kondo S, Takahashi C, Noda M, Nakajima Y (2004) The membrane-anchored matrix metalloproteinase (MMP) regulator RECK in combination with MMP-9 serves as an informative prognostic indicator for colorectal cancer. Clin Cancer Res 10(16): 5572-5579.

Tsuchida A, Ohno S, Wu W, Borjigin N, Fujita K, Aoki T, Ueda S, Takanashi M, Kuroda M (2011) miR-92 is a key oncogenic component of the miR-17-92 cluster in colon cancer. Cancer Sci 102(12): 2264-2271.

Ventura A, Young AG, Winslow MM, Lintault L, Meissner A, Erkeland SJ, Newman J, Bronson RT, Crowley D, Stone JR, Jaenisch R, Sharp PA, Jacks T (2008) Targeted deletion reveals essential and overlapping functions of the miR-17 through 92 family of miRNA clusters. Cell 132(5): $875-886$.

Venturini L, Battmer K, Castoldi M, Schultheis B, Hochhaus A, Muckenthaler MU, Ganser A, Eder M, Scherr M (2007) Expression of the miR-17-92 polycistron in chronic myeloid leukemia (CML) CD34 + cells. Blood 109(10): 4399-4405.

Woods K, Thomson JM, Hammond SM (2007) Direct regulation of an oncogenic micro-RNA cluster by E2F transcription factors. J Biol Chem 282(4): 2130-2134.

Wu W, Fan YH, Kemp BL, Walsh G, Mao L (1998) Overexpression of cdc25A and cdc25B is frequent in primary non-small cell lung cancer but is not associated with overexpression of c-myc. Cancer Res 58(18): 4082-4085.

Xie TX, Wei D, Liu M, Gao AC, Ali-Osman F, Sawaya R, Huang S (2004) Stat 3 activation regulates the expression of matrix metalloproteinase- 2 and tumor invasion and metastasis. Oncogene 23(20): 3550-3560.

Yeh HH, Lai WW, Chen HH, Liu HS, Su WC (2006) Autocrine IL-6-induced Stat 3 activation contributes to the pathogenesis of lung adenocarcinoma and malignant pleural effusion. Oncogene 25(31): 4300-4309.

Zhang X, Chen J, Radcliffe T, Lebrun DP, Tron VA, Feilotter H (2008) An array-based analysis of microRNA expression comparing matched frozen and formalin-fixed paraffin-embedded human tissue samples. J Mol Diagn 10(6): 513-519.

This work is published under the standard license to publish agreement. After 12 months the work will become freely available and the license terms will switch to a Creative Commons AttributionNonCommercial-Share Alike 3.0 Unported License.

Supplementary Information accompanies this paper on British Journal of Cancer website (http://www.nature.com/bjc) 